the catalog, however, are these basic questions: Is the expansion of the LC Catalog into a current catalog of American library resources a desirable development? If so, is the time ripe for this development? If so, would the present subscribers be willing to pay twice what they now do in order to get this tool? If not, to what extent should subsidy be sought? In what direction? With what prospects of success?

It is up to you and your confreres who are present or potential subscribers to the Catalog to answer these questions. If we are really to expand the Catalog in 1954 we need to know the answers fairly soon.

I hope that you will be willing to give this matter serious thought and that you will bring the proposal to the attention of your local and regional library organizations so that later, when the time comes for the Library of Congress to distribute a prospectus and a questionnaire, opinion may have reached a state of crystallization. In the meantime, the Library of Congress will be glad to receive your comments, questions, suggestions and the like. If you care to write, I suggest that you address your letters to John W. Cronin, Director of the Processing Department.

\title{
The Reproduction of the National Union Catalog
}

\author{
Dr. David is director, University of Penn- \\ sylvania Library.
}

$\mathrm{T}$ HERE IS A FASCINATION about the concept of a vast and all-inclusive bibliography of the printed output of the mind of man. We are all familiar with the unsuccessful attempts of some of the earlier bibliographers, who felt themselves adrift on a vast ocean of print, to produce such an index. As an example, though by no means the earliest, I may cite the Mare Magnum of the learned Florentine abbot, Francesco Marucelli, who died in 1703 , leaving his work incomplete in I I manuscript volumes.

In spite of failures the dream persisted, and what was acknowledged to be impossible by individual effort was undertaken by cooperation. Little encouragement is, perhaps, to be derived from the experience of the International Institute of Bibliography (founded in I 895 at Brussels) and its Bibliotheca Universalis. But the Gesamtkatalog der Pruessischen Bibliotheken of the Prussian State Library, which got under way in 1898 and began to be printed in I93I, has a much more encouraging record. Though wrecked by World War II, it would in a better world have been an undoubted success. Though at first legally and practically limited to Prussian libraries, it was inspired by the concept of a much broader inclusiveness, and in the end it was expanded to include all the important research libraries of Germany, and even Austria was in process of being drawn into it. $\mathrm{Had}$ disaster been averted we would in fact have had a major portion of a manageable world bibliography.

Contemporaneously, American librarianship began to press for an expansion of the Union Catalog at the Library of Congress which would bring it to what was optimistically called "completion," and some minds began to entertain the thought of its publication in this expanded form, so that it could be made generally available to research libraries in various parts of the country. The key to success in such vast operations was of course to be found not only in the magic of cooperative effort but also in the technical revolution in communication with which we are all at least in some degree familiar.

In 1947 two Philadelphia librarians went still further out on a limb and in a brief article in the Journal of Documentation outlined a plan for a Cumulative World Thesaurus to be printed and widely distributed among research libraries all over the world. ${ }^{1}$ In the light of the current rise in the cost of every library and publishing operation, the most charitable judgment which could be passed upon that article would seem to be that it may have been far in advance of its time.

1 David, C. W., and Hirsch, Rudolf, "A Cumulative World Thesaurus,", in Journal of Documentation, III $(1947), 43-45$. 
But meanwhile, in spite of all difficulties, interest in the possibility of the reproduction and distribution of the Union Catalog at the Library of Congress in some form has persisted. The files of the Library of Congress, to which your reporter has had access, reveal that the subject has been under serious consideration there for more than a decade. As early as July, 1942 there was discussion and correspondence between Mr. Schwegmann and $\mathrm{Mr}$. Boni concerning the possibility of a microprint reproduction which would be subscribed to by research libraries. The thought of a reproduction on microfilm doubtless goes back to an even earlier date; and subsequently consideration has inevitably been given to reproduction by other media such as microcards, miniature photo-offset, and fully legible photooffset.

The matter was made the subject of a considerable discussion at the Atlantic City regional conference of the ALA in October 1949. ${ }^{2}$ Shortly before this there had been published in the LC Information Bulletin an important report by Robert B. Downs which recommended reproduction. ${ }^{3}$ Almost simultaneously Fremont Rider had made to the Librarian of Congress a rather definite proposal for a microcard reproduction which was appealing enough to induce $\mathrm{Mr}$. Evans to ask the executive secretary of the ARL to find out whether the member libraries would be likely to be interested in such a reproduction to the extent of creating a market for it.

In all of the discussions of 1949 two objectives were kept in mind, viz., the need to have the Catalog reproduced for security reasons (lest the original be wiped out in some disaster), and the need to make it available to research libraries outside of Washington for a variety of bibliographic uses. The many difficulties (apart from sheer cost) surrounding any form of reproduction were also emphasized. The Library of Congress has lacked the resources to edit the Catalog as it ought to be edited before publication. It has even lacked the resources to keep it filed upto-date, and therefore there is a large backlog of unfiled cards. Resources have also been wanting to bring the Catalog to an acceptable degree of completeness. Also many of the

${ }^{2}$ An unpublished "brief interim report" [by F. H. Wagman] made at the ACRL University Section Meeting, Atlantic City, October 3, I 949.

' Downs, R. B., "Report and Supplementary Report on the National Union Catalog and Related Matters," being Appendix to the LC Information Bulletin, August 9-I 5, I 949 , p. I-3 cards in the Catalog are of such a character as to require retyping before they can be successfully reproduced by a mass photographic operation.

While these matters were under serious discussion the deterioration of our foreign relations produced one important development: as a security measure the Library of Congress was provided with funds to have the Union Catalog microfilmed, and it was in fact microfilmed in the spring of 1952-microfilmed "as is," without further expansion, without the filing of the backlog, without editing, and even without the retyping of unsatisfactory cards. ${ }^{4}$ The effect of this has undoubtedly been to take some steam out of the boiler so $f a r$ as the movement for the publication of the Catalog is concerned. The security argument is no longer seriously important. Also the existence of the microfilm negative and the willingness of the Library of Congress to provide positive copies at a fair price has given an opportunity to make a practical test of the attitude of American librarianship toward one form of reproduction. And it has to be reported that so far only one library has indicated an interest in obtaining a positive film copy, and even here no decision has yet been made. ${ }^{5}$ I fear, it must, therefore, be concluded that, except as a security measure, the filming of our national Union Catalog in its present condition is not the great forward step which it seems to a good many librarians and others to be required.

It is to this far greater enterprise that the remainder of this paper is devoted.

In the spring of 1952 a sub-committee of the ALA Board on Resources, chairmanned by your reporter, undertook a serious investigation of the possibility of the reproduction and publication of the National Union Catalog (NUC) in an expanded, well-edited, and legible form. The Library of Congress was approached and found to be highly sympathetic and willing to give every possible assistance. The method proposed for the investigation was essentially that of sampling. That is to say, the Library of Congress was asked to select a small segment of the alphabet and then to carry through (while keeping careful records) the actual operations of editing, preparing copy, and printing-with a view to displaying specimen pages of the finished work

4 Letter of George Schwegmann to the present writer, June I, I953.

$\checkmark$ Ibid. 
and of compiling cost statistics. It was also believed (and this did indeed prove to be the case) that this method would reveal in conc1ete form problems which might otherwise have been overlooked. The Library of Congress has been beyond praise in the patience, intelligence and industry with which it has gone about this assignment; and if the results achieved have not always appeared convincing, that has not been because of want of effort, but because of the difficulties of the problems under attack and the necessity, on numerous occasions, of relying on approximate estimates rather than upon established data.

Two meetings of the sub-committee with LC representatives were held at the $\mathrm{New}$ York Public Library, one in June, 1952, and the other in January, 1953. ${ }^{6}$ At first, there was pretty general, though not quite unanimous, agreement that the contemplated reproduction would be highly desirable and of great value, particularly for use in acquisitions, cataloging, the handling of interlibrary loans, and in reference and research work.

As to the scope and plan of the reproduction, it was agreed that it would be very desirable to have the Library of Congress Author Cata$\log$ expanded as of an agreed date, say 1950 or 1952, to include all imprints currently reported to the NUC for the first time, thereby making it no longer necessary to enter such imprints in the existing NUC. This proposal for an expanded Author Catalog is still under very sympathetic investigation at the Library of Congress. An ad hoc committee there has held frequent meetings on the subject over a period of many months and has drafted an extended report. It is to be hoped that in due course the report will be found acceptable and the expanded Author Catalog will become a reality.

As for the retrospective NUC, the subcommittee considered various possible expedients for breaking down so vast an enterprise into more manageable parts, e.g. a division by century of imprint, on the theory that this would permit the application of varying standards of description in accordance with bibliographical difficulties; but in the end it was decided that it would be best to try to go forward without subdivision. It was, however, decided that the magnitude of the enterprise might be reduced somewhat by the ex-

B Reports of these meetings, though not published, were reproduced for information as Appendices in the minutes of the 39 th and 4 oth meetings of the ARL (June, I952 and February, I953). clusion, subject to certain limitations, of serial publications (including government serials, federal, state and local), newspapers, music scores, manuscripts, paged analytics, and probably also atlases; also that it might be further reduced by the inclusion of LC cards only in short-title form, and by the inclusion of textbooks and multiple editions of standard works, such as Adam Smith's Wealth of Nations, only in extremely compressed form. It was hoped that by such exclusion and compression the total number of entries in the proposed printed Catalog could be reduced to perhaps $6,000,000$, of which roughly $3,200,000$ would be in shortened form.

Though the Library of Congress had, as requested, experimented with such a legible printed catalog for a short section of the alphabet and had attempted to make cost estimates, it was felt that the data so far obtained were inadequate and that further study was necessary. It was therefore requested that these experiments be repeated, due account being taken of the exclusions and compressions which the sub-committee had proposed, and that care be taken to make a clear distinction between routine or clerical operations, which could be performed by sub-professional labor, and editorial work which would have to be handled by experts. The Library of Congress was also requested to make an estimate of the cost of "completing" the NUC as a preliminary to the contemplated reproduction.

During the next six months the Library of Congress undertook to carry out these two assignments. The results were presented in documents which were considered by the subcommittee at its second meeting last January. The documents are too complex and statistical for presentation in such a paper as this, but they may perhaps be summarized. ${ }^{7}$

First, an estimate was given of the cost of "completing" the NUC in accordance with the proposals made by Robert B. Downs in July, 1949. It was calculated that such a procedure would result in the addition of I,500,000 new entries in the Catalog (plus a great number of new locations) but that the cost would amount to $\$ 1,212,318$. It was further estimated that the addition of these $1,500,000$ new entries would result in added editorial and publication costs for the contemplated reproduction amounting to $\$ 675,000$.

As for its other and more important assign-

7 The documents were reproduced in the Appendix to the 4 oth meeting of ARL referred to in note 6. 
ment, the Library of Congress explained in some detail what it had done, and then presented a number of specimen pages which illustrated the results achieved. Finally it presented in some detail an estimate of the cost of editing and publishing the NUC. ${ }^{8}$ The total mounted up to the staggering figure of $\$ 4,458,955$ for an edition of 1000 sets of 89 volumes each, or to a price of $\$ 4,458.95$ per set if the entire edition could be sold.

The documents submitted by the Library of Congress were considered at some length by the sub-committee at its January meeting.

It was realized at once that the magnitude of the enterprise of "completing" the NUC as envisioned by $\mathrm{Mr}$. Downs was so great and costly as to seem out of the question as a preliminary to the reproduction which the sub-committee had in mind. Little further attention, therefore, was given to it.

On the other hand, in its estimate of the cost of editing and publishing the NUC, the Library of Congress had been encouraged by the sub-committee to include as "preliminary operations" a partial "completion" of the Catalog. These preliminary operations and the estimates for them were discussed at some length. It was pointed out that it would be of much importance to include a great number of cards not yet reported from Harvard, and that therefore the estimated cost of these preliminary operations would in all probability have to be increased. On the other hand, the view was taken that these preliminary operations, however desirable, were not properly a part of the reproduction enterprise then under consideration and ought not to be permitted to stand as a financial obstacle in the way of its success. Rather it was felt that the "completion" of the NUC, particularly such an item of it as the filing of a large arrearage of unfiled cards, was really the business of the Library of Congress and an obligation of the federal government. However, the Library of Congress spokesmen pointed out that appropriations for this work had been repeatedly refused by Congress over the past ten years and that it had never been clearly established as a principle that the federal government has an obligation to provide for such work. One member of the sub-committee observed, on the other hand, that no plan had ever yet been implemented for the libraries of the country to support the NUC.

8 See the appendix below.
Perhaps the most serious matter brought to light during the discussion of "preliminary operations" was the estimate of 9,000,000 entries which would remain in the NUC to be published after all the contemplated exclusions and compressions-a figure which is to be compared with the $6,000,000$ estimate which the sub-committee had made at its meeting six months earlier. This figure was regarded as staggering but nevertheless valid in the light of the most recent calculations which the $\mathrm{Li}$ brary of Congress had made.

Attention was then directed to a great item of $\$ 2,800,000$ which the Library of Congress had calculated for "editing for publication." The view was expressed that this figure, which was based on an estimate of 32 cents per entry, was excessive. Some members of the sub-committee mentioned figures as low as ten cents an entry, though these were thought to be pretty certainly too low. Mention was made of the possibility of organizing the enterprise less expensively by placing it under an independent management which would cooperate closely with the Library of Congress but be separate from it, and therefore would escape some of the costliness which seems inherent in the operations of a government agency. Finally, as a kind of "wild guess," the view was expressed that the editorial cost might conceivably be got down to as little as $\$ 1,200,000$.

But even at this reduced figure, would there really be any hope of finding a subsidy adequate to make it possible to carry this project through to successful completion? If one were to eliminate entirely the cost of "preliminary operations" and to reduce editorial costs from $\$ 2,800,00$ to $\$ 1,200,000$, the cost of the total enterprise for an edition of 1000 sets would still be in the nature of $\$ 2,200,000$. Foundations were considered as possible sources of a subsidy, but no one appeared to believe that support on a large enough scale could be found in that quarter. An adequate federal subsidy was also not to be thought of in the present temper of Washington.

The final conclusion, therefore, was that while the sub-committee was of the opinion that the publication of the NUC in a convenient legible form would be highly desirable, the cost appeared to be prohibitive, there being no present prospect of finding the amount of money which the project would require.

Some thought was then given to the possi- 


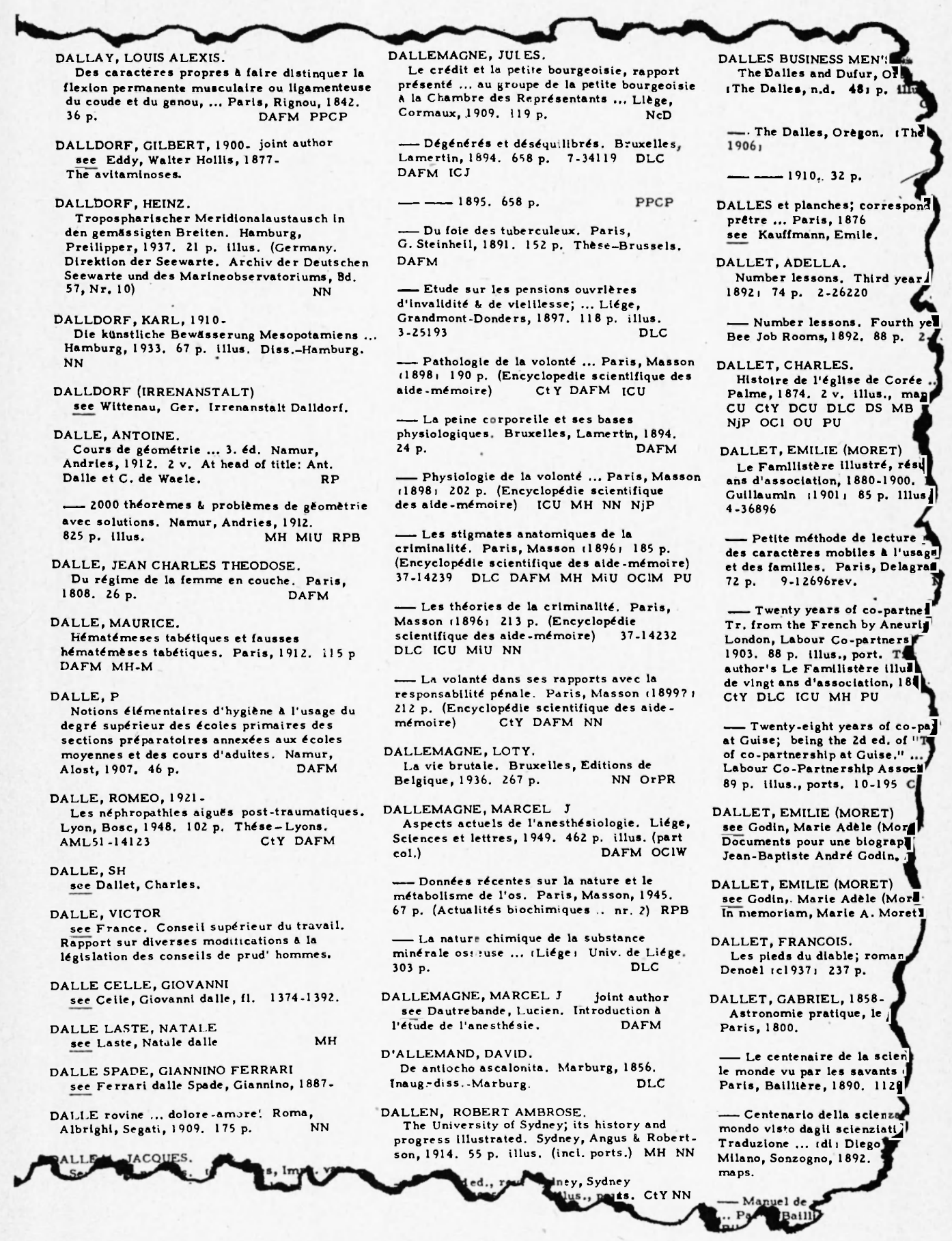

One-quarter of one of the specimen pages referred to in the text. It is reduced by $57 \frac{1}{2}$ per cent from the size of the original copy on cards. 
bility of attempting something on a much smaller scale which would still be of value. It might, for example, be useful and manageable to attempt a catalog of personal names and titles only, leaving the complex problems of corporate entries for some other solution. Also author and title entries which pose very complex editorial problems might be omitted or postponed. But such partial or makeshift solutions were clearly not a part of the subcommittee's assignment, and they were therefore not pursued.

The meeting of the sub-committee ended on a somber note. Its chairman was directed to present a final report to the Board on $\mathrm{Re}$ sources and to ask that it be dismissed. This has in due course been accomplished, and the present paper has been in large part based on the final report.

Yet, experienced librarians will hardly be willing to write finis upon this project and condemn it to the musty files of the forgotten. There is real hope that the expanded Author Catalog (which would constitute a landmark in the Union Catalog's development) will in the not distant future become a reality. As for the retrospective Catalog, there are certainly influential librarians both on the LC staff and elsewhere who, in spite of the difficulties, do not believe that the ambition to publish this great instrument in an improved and readable form must be finally abandoned.

In the opinion of your reporter it is an obligation of the federal government (though this may require considerable persuasion) to provide the Library of Congress with adequate funds to "complete" the NUC, to file the cards into it, and to edit it to the extent of making it a far better bibliographical instrument than it has ever been before. To accomplish this, he feels, ought not to be an obligation of American librarianship. If this much could be achieved at federal expense, then the cost of publishing the NUC in readable form for the use of research libraries and scholars everywhere, while still a gigantic task, would certainly be less formidable. It would doubtless still, with present methods, not be practical as a commercial or self-liquidating venture; some form of subsidy would presumably still be necessary, though it is to be hoped that it would not be impossibly great. It is the conviction of your reporter that the dream of an expanded, improved, and properly legible NUC will persist and that in a better day the means will be found to make this dream a reality-thus providing in the research libraries of this country a manageable thesaurus of approximately our total bibliographical resources, which, like the Gesamtkatalog in Germany (had it not been wrecked by the Second World War), would constitute a major portion of the bibliography of the printed output of the human mind. The work of the sub-committee of the ALA Board on Resources should not, therefore, it is hoped, be regarded as having recorded a failure, but rather as having established a bench-mark for the guidance of the more successful explorers and surveyors of a later time.

\section{ApPENDIX}

Estimated Cost of Editing and Publishing the National Union Catalog

\section{SUMMARY}

A. PRELIMINARY OPERATIONS

I. Microfilming and photo-enlarging 2,600,000 cards from University of California and University of Washington Libraries and the Denver and Seattle Union

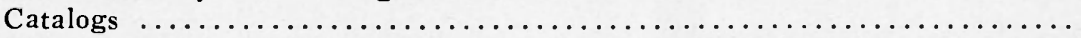

2. Filing into National Union Catalog a total of $4,800,000$ cards representing above

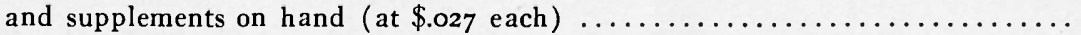

3. Pre-editing of gross National Union Catalog of $15,000,000$ cards to result in the elimination of $4,500,000$ duplicates (at $\$ .025$ each) $\ldots \ldots \ldots \ldots \ldots \ldots$

Pre-edited National Union Catalog .............. 10,500,000

Less $1,500,000$ entries for government publications, serials, music scores, manuscripts, paged analytics ........... I, 500,000

Net entries to be published $\ldots \ldots \ldots \ldots \ldots \ldots \ldots \ldots \ldots$

$9,000,000$ 